L. SCHREYER, P. S. J. KAIB, V. N. WAKCHAURE, C. OBRADORS, R, PROPERZI, S, LEE, B. LIST* (MAX-PLANCK-INSTITUT FÜR KOHLENFORSCHUNG, MÜLHEIM AN DER RUHR, GERMANY)

Confined Acids Catalyze Asymmetric Single Aldolizations of Acetaldehyde Enolates

Science 2018, 362, 216-219.

\section{Catalytic Asymmetric Mukaiyama Aldol Reaction of Acetaldehyde Enolates}

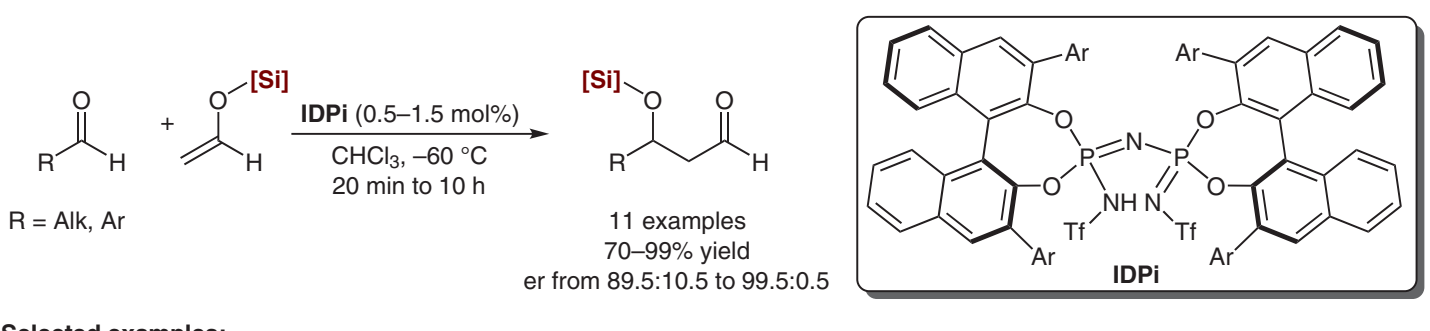

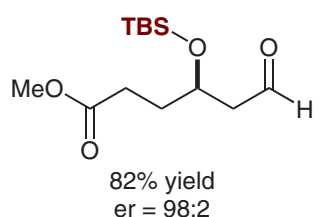

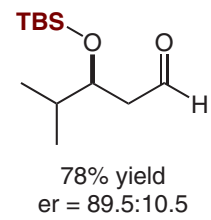<smiles>O=CCC(OS(F)(F)c1ccccc1)c1ccccc1</smiles>

\section{$95 \%$ yield} er $=99: 1$

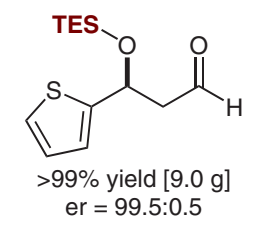

Proposed mechanism:

$$
[\mathrm{Si}]{ }_{\mathrm{O}}
$$<smiles>C=C(C)OC=CC(=O)C(C)O[AlH2]</smiles>

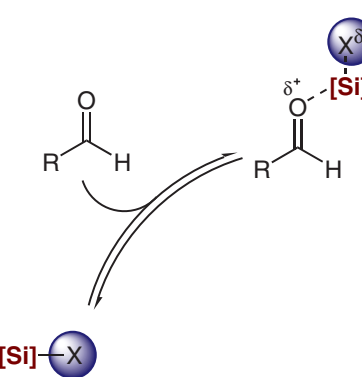

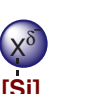

Category

Organo- and Biocatalysis

Key words

Mukaiyama aldol reaction

acetaldehyde enolates

duloxetine

asymmetric catalysis

aldolization
Significance: List and co-workers report an asymmetric Mukaiyama aldol reaction of simple silyl enolates of acetaldehyde with a variety of acceptor aldehydes. The reaction is catalyzed by imidodiphosphorimidates (IDPis) and it proceeds to form the silylated acetaldehyde aldols in good yields and excellent enantioselectivities. The authors demonstrate the synthetic utility of the method by accessing a known precursor of (S)-duloxetine. Furthermore, the authors report initial mechanistic insight and hypotheses to explain the exquisite stereo- and chemoselectivities observed.
Comment: The fundamental challenge associated with aldolization reactions of aldehydes is that the corresponding products retain the reactive functionality, often leading to uncontrolled oligomerization or polymerization of the aldol adducts. In comparison to previous reports, in which substrates are frequently designed to circumvent such challenges, the highlighted method demonstrates the power of catalyst design. Namely, the highly confined chiral pocket of the IDPi catalyst not only induces enantioselectivity, but also controls the single-addition selectivity with simple acetaldehydederived silyl enolates, a class of substrates that, hitherto, remained elusive. 